\title{
Admixing PET for the Safety of Earth Dams
}

\author{
R. Ahmadzadeh Toori' ${ }^{1}$ S. Pourbakhshian ${ }^{2}$ and M. Pouraminian ${ }^{2^{*}}$ \\ IIslamic Azad University, Science and Research Branch, Hormozgan, Iran; r_at67@yahoo.com \\ 2Department of Civil Engineering, Ramsar Branch, Islamic Azad University, Ramsar, Iran; \\ spourbakhshian@iauramsar.ac.ir,mpouraminian@iauramsar.ac.ir
}

\begin{abstract}
This article states the in vitro and analytical investigation in stability of homogenous embankment dams. Using PET recycles and studying their effects on homogeneous embankment dam's safety is the innovation of this investigation. This study includes three phases as laboratory phase, building the dam and separating lumped element model. Increasing the stability of reinforced dam by PET recycles to $21.38 \%$ than unreinforced dams is another finding of this study.
\end{abstract}

Keywords: Embankment Dam Homogeneous, Model Validation, PET, Physical Model, Shear Box Test

\section{Introduction}

Nowadays, large dams either embankment or concrete dams are among the most important buildings in providing required water, electricity and controlling floods in human communities. Thus, in last decades, engineers of embankment and concrete dams have been interested in dams' stability. The nature of natural formations stability in place of building embankment dams and complicated behavior of dam earthen material, on the other hand, make qualitative and quantitative evaluation of soil behavior parameters becomes necessary (ASCE, 2000). The main body of the dam is made of non-mortar material mixed or separated in homogenous or classified form. The basic duty of embankment dam is saving water and preventing leakage from the framework and secondly stability to the force ${ }^{2}$. Therefore, in this article, the qualitative and quantitative evaluation of earthen behavior parameters was investigated due to admixing PET. Then the embankment dam was made in flume and finally was analyzed. Low cohesion clay was used in this study. The plastic limit of this soil is 16.38 , the liquid limit is 28.65 , the plasticity index is 12.26 and the grain gravity is 2.7 ; and the soil is located in CL class. The grading curve of fine soil applied in dam model is given in Figure (1).
Though reinforcing soil has a long history, extensive studies were focused on determining and evaluating mechanical behavior of fiber reinforced soil was, in last decade. So randomly distributed fiber reinforce (RDFR) was started since early 1970s. Gary ${ }^{3}$ were among the first authors who used triaxial compression test on fiber sands to investigate reinforced soil and indicated that increasing strength harmonized to reinforcing materials. Also, Maher ${ }^{4}$ investigated on various sand samples by random method of polyethylene reinforced tapes through triaxial tests.

Benson and Khire ${ }^{9}$ studied reinforcing soil by using polyethylene tapes through CBR and direct shear tests. The findings by Ranjan et $\mathrm{al}^{5}$ on fiber reinforced samples through triaxial tests $\mathrm{Wang}^{6}$, investigations by Vang $^{6}$ while using mono-axial and tri-axial tests on the mechanical behaviors of sandy soil and reinforced high-clay soils Michalowski ${ }^{7}$, and direct shear test and tri-axial tests by Santoni and Webster ${ }^{10}$ on reinforced sandy soils, indicate that reinforced samples had more plasticity than non-reinforced ones; or increasing fibers in soil can enhance shear strength. Michalousky ${ }^{7}$ gave a criterion to separate reinforced sand with steel and polyamide by laboratorial and theatrical investigations Jigisha ${ }^{8}$. Vashia ${ }^{8}$ studied the effect of PET and

*Author for correspondence 


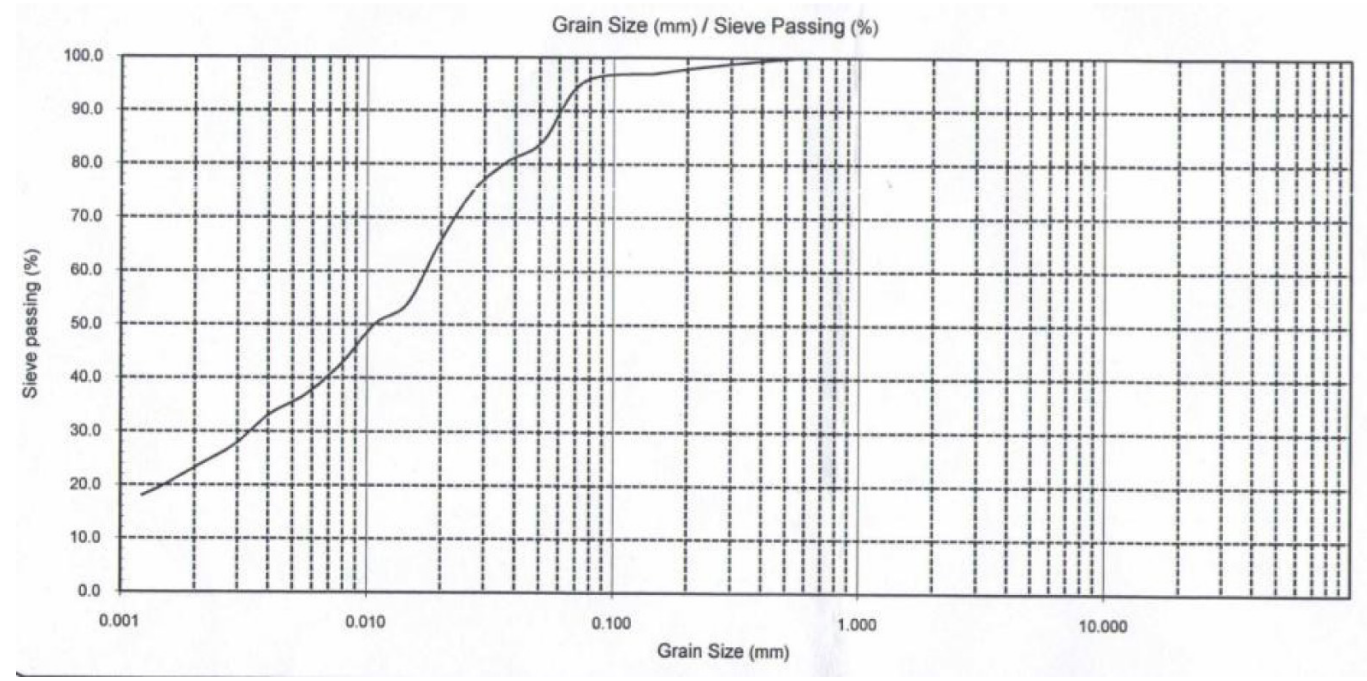

Figure 1. Curve of grading dam body soil.

Geotextile on soft soil in embankment dams and stated that using PET is better and economic and increases stability.

\section{Materials and Method}

As mentioned, this article was done in 3 sections which are stated as follows:

\subsection{Phase 1-reinforcing the Clay}

In this part, first, PET will be defined.

PET: Polyethylene terephthalate, usually known as pet is one of the most frequently used polymers that is produced by polymerization method. PET was washed on sieve number 200 to separate the cleaved particles to be prepared. Then, the PET was poured into water; so that the mixed particles to the PET were floated on water and PET was settled on the bottom of the container as specific weight of PET is more than water. After preparing PET and clay, they were admixed in determined percentages. In first test (pure clay), after doing density test by standard proctor and measuring dry unit weight and optimum moisture content and providing remolded sample (suitable sample provision method) by gathered data, direct shear tests was conducted ; the data were considered as control samples and the other results were evaluated through the tests. In next step, PET was added to clay as 0.1 clay percentage weight.

\subsubsection{The test Applied}

Compaction test: One of the important parameters in determining the soil properties is the bed compaction. A soil with low level of compaction has little value for soil bed preparation. This test is used to calculate $\gamma_{\text {dmax }}$, $\omega_{\text {opt }}$ to make a remolded sample for the experiments. The experiment is used by the standard proctor. The standard mould volum: $944 \mathrm{~cm}^{3}$, the mould caliber: $10.16 \mathrm{~cm}$.three layers of soil, the number of hammer blows 25 in each layer, weight $2.5 \mathrm{~kg}$ falling off a height of $30.50 \mathrm{~cm}$.

The direct shear test: This test is applied in three point's method, according to ASTM D3080 standard. This test in used to calculate the shear strength in soil. In this test, the result of the compaction test are used to make, remolded sample in $6 * 6 * 2$ cutter. Some vertical bars $20 \mathrm{~kg}, 40 \mathrm{~kg}, 60 \mathrm{~kg}$ in weight are installed on the sample. By a shear stress graph and a normal stress, three points were given by which the best regression line was drawn. The Y - intercept has shown the soil cohesion and the line angle to the horizontal axis has shown the internal frication angle (ASTM D3080). The equation $\tau=c+\sigma \tan \varphi$ indicates: ( which $\mathrm{c}=$ cohesion of the soil , $\varphi=$ internal friction angle, $\sigma=$ direct stress, $\tau$ is the shear stress)

The test result: In this study, the effect of pet percentage in the clay on the shear strength parameters of soil was investigated. The result of compaction is given in table (1). According to table (1), the scale of PET on unit weight of soil volume affects inconsiderably. 
Table1. Compaction Test Results

\begin{tabular}{ccc}
\hline Pet to clay ratio & \multicolumn{2}{c}{ Compaction test } \\
\cline { 2 - 3 } & $\gamma_{\mathrm{dmax}}$ & $\boldsymbol{\omega}_{\mathrm{opt}}$ \\
\hline 0 & 1.684 & 18.71 \\
0.1 & 1.689 & 17.51 \\
0.2 & 1.685 & 18.31 \\
0.3 & 1.682 & 18.67 \\
0.4 & 1.687 & 18.36 \\
0.5 & 1.687 & 18.78 \\
0.6 & 1.666 & 19.71 \\
0.7 & 1.676 & 17.58 \\
0.8 & 1.669 & 19.32 \\
0.9 & 1.688 & 16.56 \\
1 & 1.655 & 21.78 \\
\hline
\end{tabular}

\subsection{The Effect of PET Changes on Shear Parameters}

A goal of reinforcing soil is to improve its shear strength. Shear failure is used to investigate reinforced soil shear parameters that are shown by direct shear tests results. High potential of reinforcing effect on soil shear strength are given in Figures (2) and (3). Studying the diagram indicates that internal friction angle increased from $20.93^{\circ}$ in non-reinforced sample to $30.03^{\circ}$ and cohesion from 0.135 in non-reinforced sample to 0.195 .

\subsection{Phase2- introducing the Studied Dam}

The experiments were conducted in a flume with $5 \mathrm{~m}$ length and $1.5 \mathrm{~m}$ height and $1 \mathrm{~m}$ width in a laboratory. In both cases, the dam was constructed from clay with horizontal gradient 2 and vertical gradient 1 in two downstream and upstream layers with $60 \mathrm{~cm}$ height, $1 \mathrm{~m}$ width and $30 \mathrm{~cm}$ crest width and $2.70 \mathrm{~m}$ base length. 27 piezometers were applied in flume structure to measure pore pressure that is shown in Figure (4).

The soil used in whole dam body is CL type. More explanations related to physical and mechanical features of dam body soil are given in phase one. In the pet method, the soil layers with $7 \mathrm{~cm}$ height and rolling 30 times with $30 \mathrm{~kg}$ roller were provided with up-95\% density. Water was kept in $55 \mathrm{~cm}$ height for 5 days to make porous soil environment saturated. Plaxis software was used in measuring dam stability.

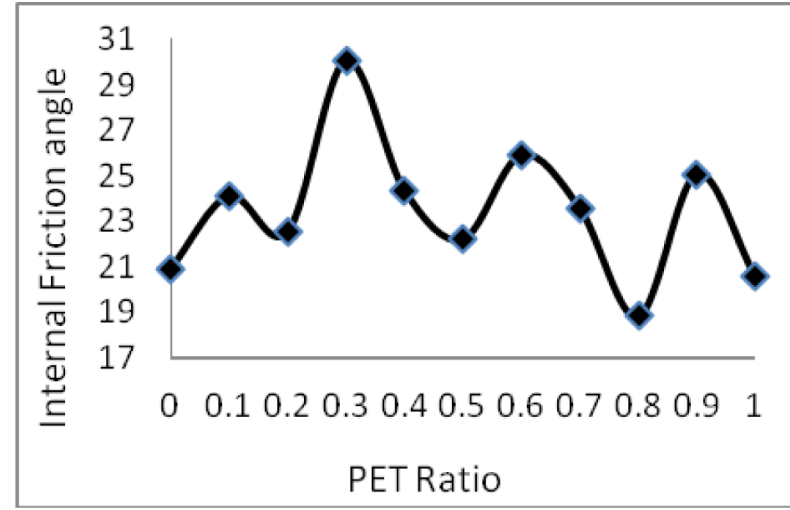

Figure 2. Effect of PET on Internal Friction angle.

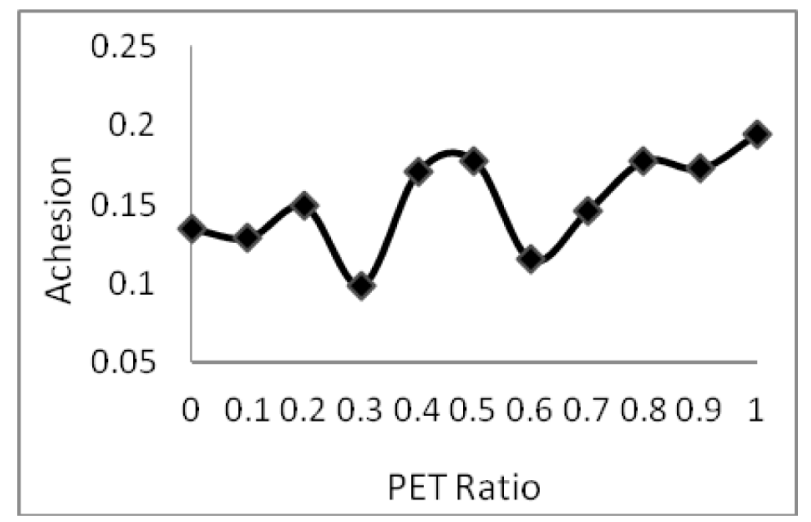

Figure 3. Effect of PET on cohesion.

\subsection{Phase3- finite Element Model}

The embankment dam was analyzed completely and homogenously through using the results of soil mechanic laboratory in two different conditions, pet admixture and base soil properties, to compare the results and studying the effect of pet material on dam body. The features of dam body soil, before and after using pet material, and also base soil properties are given in Tables 2, 3 and 4 .

\subsection{Discretization Model}

In this section, modeling and numerical analyzing of the mentioned model in previous section by numerical finite element model and Plaxis 2D were explained. Mohr-Coulomb criterion is considered as the discrete criterion in this software. The dimensions of the model are similar to the created model in soil mechanics laboratory. Working area was $3.5 \mathrm{~m}$ to positive $\mathrm{X}$ direction and $1 \mathrm{~m}$ to positive $\mathrm{Y}$ direction, for modeling soil mass. The position and dimensions of the model are given in Figure (5). 


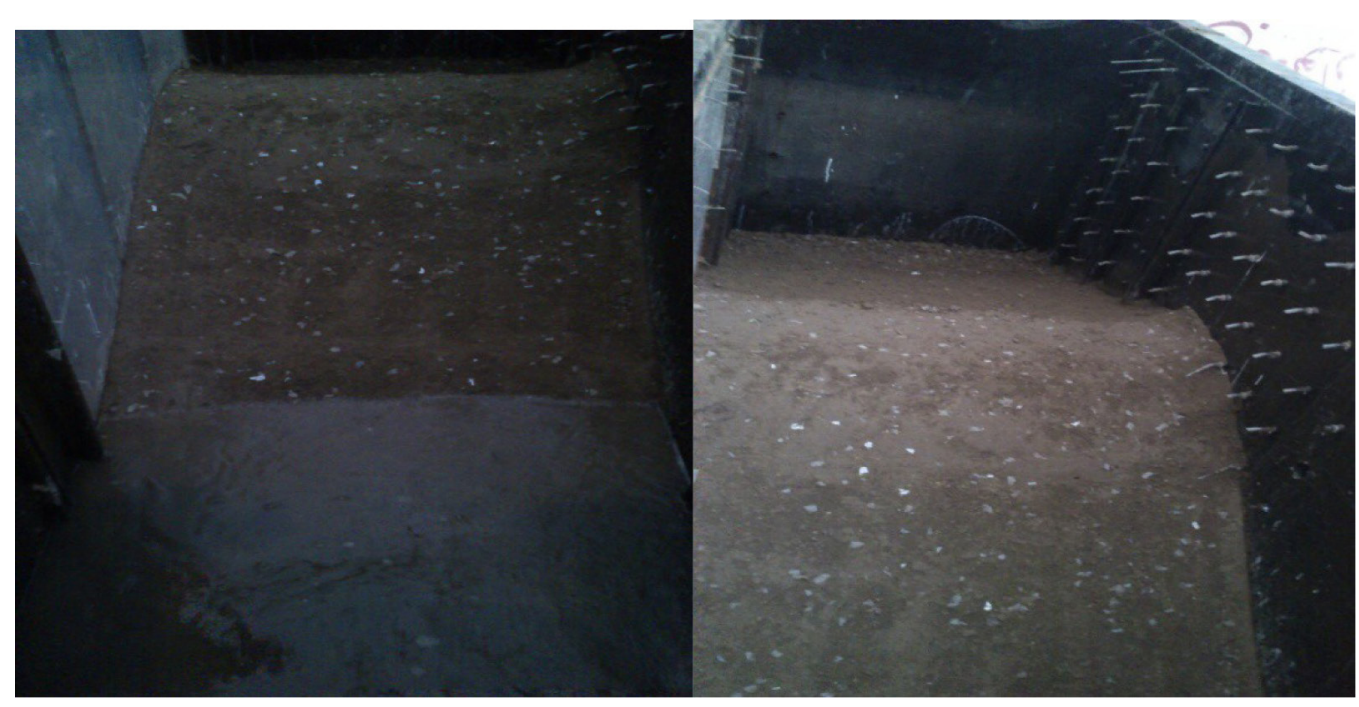

Figure 4. Laboratorial model of embankment dam (full and empty reservoir).

Table 2. Properties of dam body soil before using PET material in Plaxis software

\begin{tabular}{lccc}
\hline parameter & notation & Dam body & unit \\
\hline Constitutive model & model & $\mathrm{MC}$ & - \\
Unit weight of soil & $\gamma_{\text {unsat }}$ & 20 & $\mathrm{KN} / \mathrm{m}^{3}$ \\
Saturated unit weight & $\gamma_{\text {sat }}$ & 20.62 & $\mathrm{KN} / \mathrm{m}^{3}$ \\
Permeability-x & $\mathrm{Kx}$ & 0.027 & $\mathrm{~m} / \mathrm{day}$ \\
Permeability-y & $\mathrm{Ky}$ & 0.027 & $\mathrm{~m} / \mathrm{day}$ \\
modulus & $\mathrm{E}_{\text {ref }}$ & 35000 & $\mathrm{KN} / \mathrm{m}^{3}$ \\
Poisson' ratio & $\mathrm{V}$ & 0.3 & - \\
Soil Achesion & $\mathrm{C}_{\text {ref }}$ & 13.8 & $\mathrm{kPa}$ \\
Angle of internal friction & $\varphi$ & 20.93 & - \\
Diltancy angle & $\psi$ & 0 & - \\
\hline
\end{tabular}

Table 3. Properties of dam body soil after using PET material in Plaxis software

\begin{tabular}{lccc}
\hline parameter & notation & Dam body & unit \\
\hline Constitutive model & model & $\mathrm{MC}$ & - \\
Unit weight of soil & $\gamma_{\text {unsat }}$ & 20 & $\mathrm{KN} / \mathrm{m}^{3}$ \\
Saturated unit weight & $\gamma_{\text {sat }}$ & 20.62 & $\mathrm{KN} / \mathrm{m}^{3}$ \\
Permeability-x & $\mathrm{Kx}$ & 0.02 & $\mathrm{~m} / \mathrm{day}$ \\
Permeability-y & $\mathrm{Ky}$ & 0.02 & $\mathrm{~m} / \mathrm{day}$ \\
Elasticity modulus & $\mathrm{E}_{\text {ref }}$ & 35000 & $\mathrm{KN} / \mathrm{m}^{3}$ \\
Poisson' ratio & $\mathrm{V}$ & 0.3 & - \\
Soil Achesion & $\mathrm{C}_{\text {ref }}$ & 15.5 & $\mathrm{kPa}$ \\
Angle of internal friction & $\varphi$ & 30.3 & - \\
Diltancy angle & $\psi$ & 0 & - \\
\hline
\end{tabular}


Table 4. Properties of dam foundation in Plaxis software

\begin{tabular}{lccc}
\hline parameter & notation & $\begin{array}{c}\text { Foundation } \\
\text { soil }\end{array}$ & unit \\
\hline Constitutive model & model & $\mathrm{MC}$ & - \\
Unit weight of soil & $\gamma_{\text {unsat }}$ & 18 & $\mathrm{KN} / \mathrm{m}^{3}$ \\
Saturated unit weight & $\gamma_{\text {sat }}$ & 20 & $\mathrm{KN} / \mathrm{m}^{3}$ \\
Permeability-x & $\mathrm{Kx}$ & 0.08 & $\mathrm{~m} / \mathrm{day}$ \\
Permeability-y & $\mathrm{Ky}$ & 0.08 & $\mathrm{~m} / \mathrm{day}$ \\
Elasticity modulus & $\mathrm{E}_{\text {ref }}$ & 35000 & $\mathrm{KN} / \mathrm{m}^{3}$ \\
Poisson' ratio & $\mathrm{v}$ & 0.3 & - \\
Soil Achesion & $\mathrm{C}_{\mathrm{ref}}$ & 1 & $\mathrm{kPa}$ \\
Angle of internal friction & $\varphi$ & 33 & - \\
Diltancy angle & $\psi$ & 0 & - \\
\hline
\end{tabular}

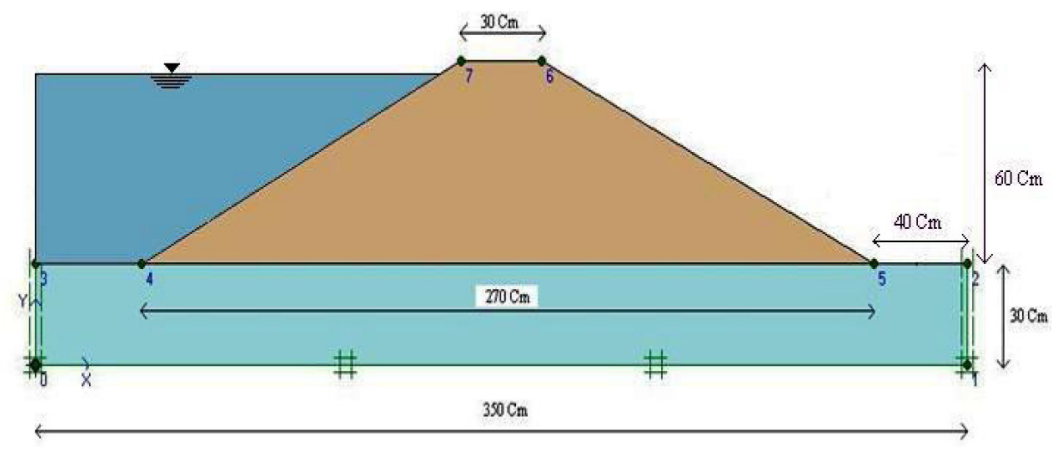

Figure 5. A view of studied dam.

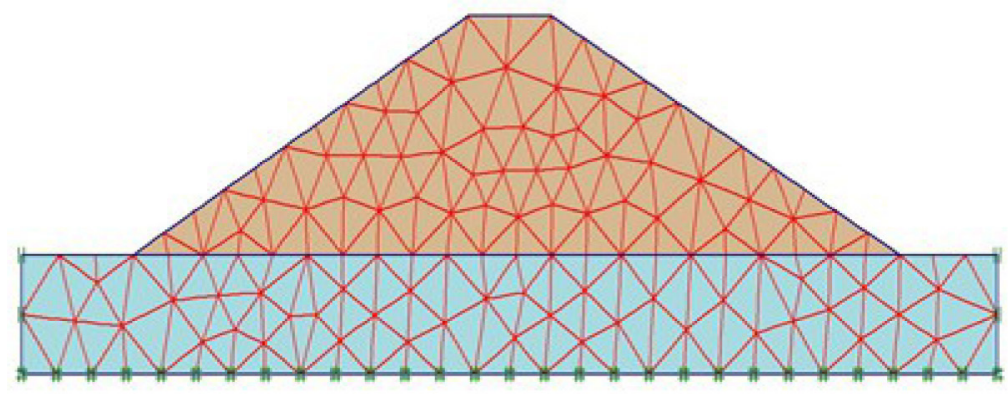

Figure 6. Meshing the studied dam.

After assigning mechanical and geometrical parameters and behavior models of dam foundation mass, the following meshing was used for numerical finite element analysis (Figure 6):

\subsection{Boundary Condition Definition}

After meshing, the modeling is done by using the finite element methods; that the boundary conditions must be applied to the model before the calculation. This is done to get to the primary balance in the model and a primary position before the calculations. This phase includes two parts: the first part is done for forcing water into the canal flow line (Figure 7) and the second phase is done for primary stress in the soil in which the software uses Jaky $\operatorname{method}\left(\mathrm{K}_{0}=1-\sin \varphi\right)$. Since the work is done on a slope, the second part can't be used and the primary stress must be created in a separate phase. 


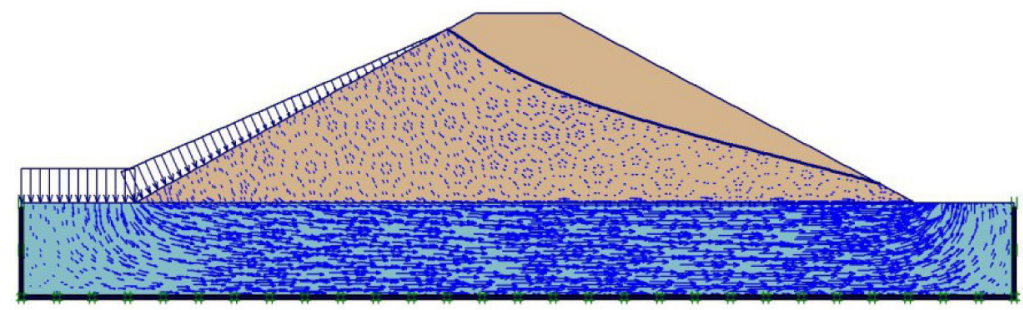

Figure 7. Pure water pressure.

\subsection{Calculations}

In order to simulate the construction phases and considering its stability, three calculative phases were adopted as follows:

Phase 1: Creating primary stresses and using plastic analysis

Phase 2: Building the foundation and body of the dam Phase 3: Using the $\varnothing / \mathrm{c}$ reductive method to analyze the dam body stability .it must be noted that any deformation due to the primary stress position (phase1) will be overlooked in the phase 2 calculations.

\subsection{Comparison of Consistency Analysis Result on the Dam Body}

In phase 3 of these calculations, the reductive $(\varnothing) / \mathrm{c}$ method was used to analyze the stability of dam body; and the results and diagrams are given. Confidence coefficient was 2.28 before adding pet material and increased to 2.9 after adding pet material (Table 5.)

In this study, the dam consistency was considered with assumptions of no failure and no slipping against hydrostatic force in the reservoir.

\section{Conclusion}

Soil reinforcement has caused reduced fragility and increased plasticity of soil. Admixture of PET had a significant effect on the dam's stability by an increase of about $21 \%$.
Table 5. PET effect on Factor of Safety

\begin{tabular}{lccc}
\hline Parameter & $\begin{array}{c}\text { Before } \\
\text { admixing }\end{array}$ & $\begin{array}{c}\text { Admixing } \\
\text { by pet }\end{array}$ & $\begin{array}{c}\text { Change in } \\
\text { F.S }\end{array}$ \\
\hline $\begin{array}{l}\text { Factor of } \\
\text { Safety }\end{array}$ & 2.28 & 2.9 & +21.38 \\
\hline
\end{tabular}

\section{References}

1. ASCE Task Committee. Guidelines for instrumentation and measurements for monitoring dam performance. ASCE, 2000

2. Rahimi, Hassan. Earth Dams. 2nd ed. Tehran university publication; 2007.

3. Gray D, Al-Refeai T. Behavior of Fabric-Versus FiberReinforced Sand. J Geotech Engrg. 1986; 112(8):804-20.

4. Maher M, Gray D. Static Response of Sands Reinforced with Randomly Distributed Fibers. J Geotech Engrg. 1990; 116(11): 1661-77.

5. Ranjan G, Vasan R, and Charan H. Probabilistic Analysis of Randomly Distributed Fiber-Reinforced Soil. J Geotech Engrg. 1996; 122(6):419-26.

6. Wang Y, Frost JD, Murray J. Utilization of recycled fiber for soil stabilization. Proceeding of the fiber society Meeting; 2000; Portugal. P. 59-62.

7. Michalowski RL, Zhao AG. Failure of fiber- reinforced granular soils. J of Geotech Engrg. ASCE, 1996; 122(3):226-34.

8. Vashia JM, Desaib AK, Solankib CH. Evaluation of PET and PP Geotextile Reinforced Embankment on Soft Soil. Procedia Engineering. 2013; 51:19-24.

9. Benson $\mathrm{CH}$, Khire MU. Reinforcing Sand with Strips of Reclaimed High-Density Polyethylene. Journal of Geotechnical Engineering. 1994; 121:838-55.

10. Santoni RL, Webster SL. Airfields and road construction using fiber stabilization of sands.Journal of Transportation Engineering. 2001. 127(2):96-104. 